\title{
Pengembangan Media Pembelajaran Berbasis Virtual Class Berbantuan Google Drive
}

\author{
Sohibun ${ }^{1}$, Filza Yulina Ade ${ }^{1}$ \\ ${ }^{1}$ FKIP Universitas Pasir Pengaraian; email: bie.idsohib@gmail.com
}

Diterima: 12 Oktober 2017. Disetujui: 12 November 2017. Dipublikasikan: Desember 2017

\begin{abstract}
University students become the main target of marketing of information technology developers. Based on the results of a survey with random sampling technique on users of wireless fidelity (wi-fi) service and internet service providers on smartphones, there are $98 \%$ of physics students use it and $80 \%$ of them actively use it to access various social media. Interactive learning media developed and accessible via smartphone but it is not widely used by lecturers and students yet. There is only $14.3 \%$ of lecturers who use e-learning. Virtual Class on e-learning is an online learning environment, in the form of web-based, portal or software. Learning in the real world, every participant both lecturers and students must meet the rules agreed upon during the college contract. One of the strategies to improve the independence of study of physics student is through learning media based on Virtual Class assisted by Google drive. Therefore, it is necessary to develop a lesson that can support conventional learning in the classroom.
\end{abstract}

\begin{abstract}
Abstrak
Mahasiswa menjadi sasaran utama marketing para pengembang teknologi informasi. Berdasarkan hasil survei yang dilakukan dengan teknik random sampling pada pengguna layanan wifi dan layanan internet provider pada gawai, terdapat $98 \%$ mahasiswa fisika menggunakannya dan $80 \%$ diantaranya aktif menggunakannya untuk mengakses berbagai media sosial. Media pembelajaran interaktif banyak dikembangkan dan dapat diakses melalui gawai. Akan tetapi, belum banyak digunakan dosen dan mahasiswa, hanya $14,3 \%$ saja dosen yang menggunakan e-learning. Virtual Class pada e-learning merupakan lingkungan belajar online, berupa berbasis web, portal atau software. Pembelajaran di dunia nyata, setiap peserta baik dosen maupun mahasiswa harus memenuhi aturan yang disepakati saat kontrak kuliah. Salah satu strategi untuk meningkatkan kemandirian belajar mahasiswa fisika adalah melalui media pembelajaran berbasis Virtual Class berbantuan Google drive. Oleh karenanya, perlu dikembangkan pembelajaran yang dapat menunjang pembelajaran konvensional di kelas.
\end{abstract}

Kata Kunci: Virtual Class, Google Drive, kemandirian belajar

๑) 2017 URPI, FTK UIN Raden Intan Lampung

\section{PENDAHULUAN}

Peningkatan kemampuan dalam
rangka penyesuaian diri dengan
perubahan dan memasuki era globalisasi
antara lain dapat dilakukan melalui
peningkatan kemampuan siswa dalam
belajar fisika (Mihardi \& Derlina, 2015).
Penyebab rendahnya hasil belajar yaitu
pemilihan metode dan media pembelajaran yang digunakan oleh guru pada proses pembelajaran sangat kurang tepat dan pengelolaan kegiatan pembelajaran yang masih belum dapat membangkitkan motivasi belajar siswa secara optimal (Gumrowi, 2016). Media sendiri adalah sebagai alat komunikasi guna lebih mengefektifkan proses belajar mengajar (Mahbub, Kirana, \& 
Poedjiastoeti, 2016; Woodrich \& Fan, 2017). Manfaat dari penggunaan media ini diharapkan mampu menarik perhatian siswa dan memudahkan siswa dalam memahami materi (Eko Purwanto, Hendri, \& Susanti, 2016). Internet dapat memberikan pengayaan dan komunikasi antara mahasiswa dengan dosen, sesama mahasiswa, atau mahasiswa dengan narasumber lain (Asyhari \& Diani, 2017).

Pembelajaran akan memberikan hasil yang lebih baik jika didesain sesuai cara manusia belajar (Gunawan, Harjono, \& Imran, 2016). Berdasarkan laporan Simon Kemp dalam South East Asia Digital in 2015, hingga November 2015 pengguna internet telah mencapai 88,1 juta orang atau sekitar $34 \%$ dari total jumlah penduduk Indonesia (Irwandani, 2016). Menurut hasil survey yang dilakukan Asosiasi Pengusaha Jasa Internet Indonesia (APJII) bersama PUSKAKO MUI tahun 2014 menunjukan bahwa banyaknya pengguna internet perwilayah seperti pada Gambar 1 berikut ini.

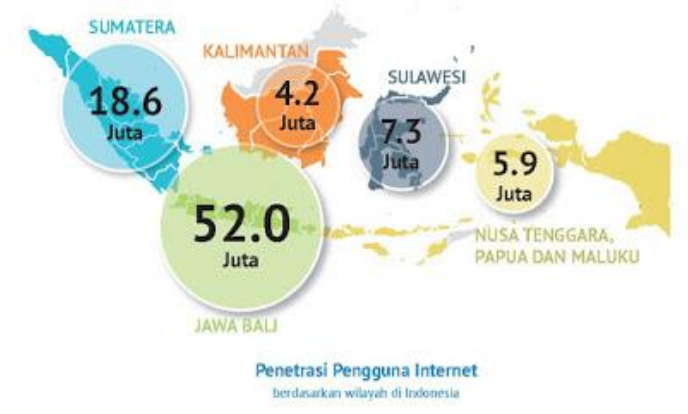

Gambar 1. Sebaran Pengguna Internet.

Berdasarkan Gambar 1 di atas diketahui 88 juta masyarakat Indonesia aktif menggunakan jasa internet. Dari 7.000 respon disurvei, terdapat $85 \%$ diataranya mengakses internet melalui ponsel selulernya, mengungguli penggunaan internet melalui laptop, PC maupun tablet.

Akan tetapi, kemajuan teknologi informasi tersebut tidak dibarengi dengan penggunaan yang optimal pada ranah pendidikan (perkuliahan). Hasil penelitian tersebut sejalan dengan hasil observasi yang dilakukan dengan menggunakan teknik random sampling berdasarkan wawancara tak terstruktur.

Padahal disisi lain, kompetensi Abad 21 menuntut agar peserta didik terlibat langsung dalam proses pembelajaran yang memanfaatkan fasilitas internet, dimana peserta didik bukan hanya sebatas mencari informasi, tapi peserta didik juga melaksanakan pembelajaran secara online (Wijayanti, Maharta, \& Suana, 2017). Meluasnya pemanfaatan internet bisa menjadi potensi besar dalam pengembangan pembelajaran dengan sistem online (Yuberti, 2015).

Kondisi tersebut potensial untuk dilakukannya pembelajaran yang tidak menuntut waktu dan tempat. Pembelajaran ini sering diistilahkan $e$ learning. (Eliana, Senam, Wilujeng, \& Jumaidi, 2016). Sisi baik dari penggunaan e-Learning adalah mahasiswa dituntut menjadi lebih aktif dibandingkan pengajaran secara tradisional. Memberikan jalan menuju sistem belajar mengajar yang berpusat pada mahasiswa (Student Center learning).

Perkembangan teknologi yang sangat pesat ini, harus selaras dengan peningkatan mutu SDM agar arah perkembangan ilmu pengetahuan dan teknologi dapat menuju sasaran yang tepat (Mulyadi, 2015). Harapan adanya kemajuan ilmu pengetahuan dan teknologi yang sangat pesat, akan mampu terbentuknya karakter peserta didik yang kuat dan kokoh yang diyakini merupakan hal penting dan mutlak dimiliki anak didik untuk menghadapi tantangan hidup masa depan (Rohmani, Sunarno, \& Siti Amanah, 2015).

Saat ini, virtual class sudah mulai dijadikan alternatif pembelajaran. Hal ini dikarenakan pembelajaran ini tidak lagi terikat oleh ruang dan waktu. Akan 
tetepi, virtual class tidak serta merta menggantikan perkuliahan konvensional karena masing-masing mempunyai kelebihan dan kekurangan. Namun, dalam hal ini virtual class diharapkan menjadi penunjang proses pembelajaran dikelas secara konvensional, apa yang tidak tersampaikan di kelas konvensional dapat disampaikan melalui virtual class.

Berdasarkan uraian di atas, tujuan penelitian ini yaitu mengembangkan inovasi e-learning untuk menghasilkan produk media pembelajaran Virtual Class. Pembelajarn tersebut dipadukan dengan bantuan Google Drive sebagai sarana penunjang perkuliahan di Prodi Pendidikan Fisika Universitas Pasir Pengaraian (UPP). Capaian dari penelitian ini adalah pembelajaran Virtual Class berbantuan Google Drive yang efektif sebagai sarana penunjang perkuliahan mahasiswa Prodi Pendidikan Fisika UPP.

\section{METODE PENELITIAN}

Penelitian yang dilakukan ialah penelitian pengembangan yang bertujuan untuk menghasilkan produk berupa media pembelajaran berbasis Virtual Class. Metode penelitian dan pengembangan (Research and Development) adalah metode penelitian yang digunakan untuk menghasilkan produk tertentu dan menguji keefektifan produk tersebut (Sugiyono, 2013).

Sejalan dengan itu, menurut Sukmadinata (2008) penelitian dan pengembangan adalah suatu proses atau langkah-langkah untuk mengembangkan suatu produk baru atau menyempurnakan produk yang telah ada, yang dapat dipertanggungjawabkan. Jadi, dapat disimpulkan bahwa penelitian pengembangan adalah penelitian yang bertujuan menghasilkan suatu produk yang harapannya akan efektif untuk digunakan berdasarkan kebutuhan pendidikan yang banyak berkembang pada saat ini.

\section{A. Model Pengembangan}

Penelitian ini diharapkan dapat menghasilkan suatu produk yang dapat meningkatkan pemahaman konsep fisika dan kemandirian belajar mahasiswa diprogram studi pendidikan fisika UPP. Model pengembangan yang digunakan dalam penelitian ini adalah model yang dikembangkan oleh Sugiyono (Sugiyono, 2013).

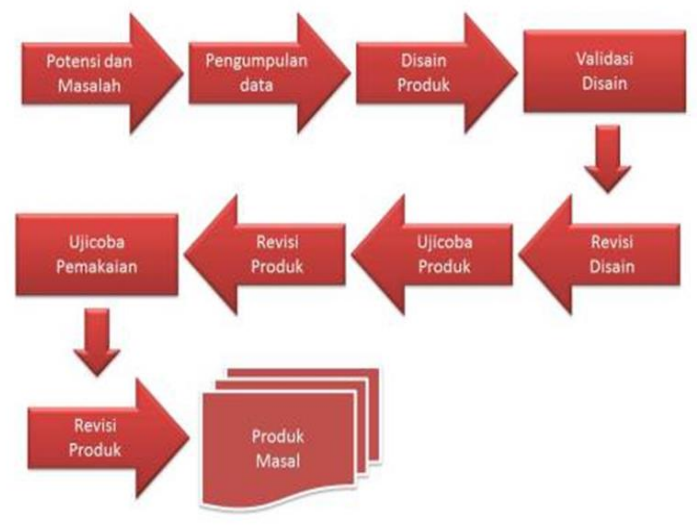

Gambar 2. Langkah-langkah Penggunaan Metode Research and Development

\section{B. Langkah-langkah Pengembangan}

Bahan ajar interaktif ini dikembangkan dengan menggunakan beberapa tahap. Tahap-tahap pengembangannya diuraikan sebagai berikut.

\section{Potensi dan Masalah}

Penelitian berangkat dari adanya potensi dan masalah yang ada di program studi pendidikan fisika UPP. Potensi adalah segala sesuatu yang bila didayagunakan akan memiliki nilai tambah, sedangkan masalah adalah penyimpangan antara yang diharapkan dengan yang terjadi (Sugiyono, 2013). Potensi yang dapat dimanfaaatkan melalui penelitian ini adalah pemanfaatan teknologi informasi, internet dan lain sebagainya.

Masalah yang ada pada pembelajaran konvensional di ruang kelas adalah waktu dan ruang gerak yang terbatas. Dengan memanfaatkan 
berbagai sumber belajar yang ada, didukung dengan adanya laboratorium komputer yang bisa didayagunakan untuk mendukung penggunaan Virtual Class berbantuan Google Drive, sehingga nantinya dapat membantu dosen dan mahasiswa dalam proses pembelajaran fisika pada era pendidikan yang berlaku sekarang ini. Oleh karena itu, dalam pengembangan ini akan dikembangkan media pembelajaran berbasis Virtual Class berbantuan Google Drive.

\section{Pengumpulan Data}

Pada tahap pengumpulan data dilakukan pengumpulan bahan-bahan yang diperlukan pada saat proses pembuatan media pembelajaran berbasis Virtual Class berbantuan Google Drive. Adapun pengumpulan bahan seperti materi pelajaran, gambar, foto, jenis huruf yang akan digunakan, dan lain-lain yang diperlukan untuk tahap berikutnya.

\section{Desain Produk}

Tahap ini dimaksudkan untuk membuat spesifikasi secara rinci mengenai desain awal produk, gaya, dan kebutuhan material untuk produk pengembangan media pembelajaran berbasis Virtual Class berbantuan Google Drive yang disertai dengan adanya video dan animasi multimedia. Adapun rancangan awal produk adalah sebagai berikut.

Nama Produk : Media Pembelajaran berbasis Class berbantuan Google Drive

Mata Kuliah : Fisika

Pengguna : Dosen dan Mahasiswa Isi Media Pembelajaran:

1. Bagian Awal
a. Home
b. Login
c. Search
d. Tentang Kami

2. Bagian Isi a. Dashboard
b. Master Materi
c. Master Mahasiswa
d. Perkuliahan
e. Presensi
f. Vchat

\section{Validasi Desain}

Setelah tahap pembuatan desain dan produk bahan ajar interaktif, dilakukan tahap validasi baik validasi isi maupun konstruk. Tahap validasi desain ialah tahap penilaian apakah produk yang telah dirancang sudah bersifat rasional atau tidak. Validasi desain ini dilakukan dengan cara menghadirkan ahli bidang studi fisika komputasi, ahli pendidikan dan ahli multimedia yang sudah berpengalaman. Kegiatan ini juga bertujuan untuk menilai apakah bahan ajar interaktif tersebut sudah layak atau tidak untuk uji coba produk.

\section{a. Ahli Fisika Komputasi}

Beberapa dosen Jurusan Pendidikan Fisika sebagai ahli yang harapannya dapat memberikan penilaian awal dan masukan dari sudut pandang materi (kesesuaian materi menggunakan komputasi) atau konsep fisika mengenai media pembelajaran berbasis Virtual Class berbantuan Google Drive yang telah dikembangkan.

b. Ahli Pendidikan

Ahli pendidikan yang berperan dalam penilaian ini berasal dari lingkungan dalam kampus UPP dan Universitas Riau yang diharapkan bisa memberikan penilaian awal dan masukan mengenai model pembelajaran dengan media pembelajaran berbasis Virtual Class berbantuan Google Drive.

c. Ahli Multimedia

Ahli multimedia ini berasal dari lingkungan luar dan lingkungan dalam FKIP UPP. Dari ahli tersebut diharapkan dapat memberikan penilaian awal dan masukan mengenai media pembelajaran berbasis Virtual Class berbantuan Google Drive yang sudah dibuat. 


\section{Perbaikan (Revisi)}

Tahap ini dilakukan setelah proses validasi oleh para ahli fisika komputasi, ahli pendidikan dan ahli multimedia sehingga nantinya akan mendapatkan hasil berupa masukan komentar, kritik sampai dengan saran-saran demi penyempurnaan bahan ajar interaktif. Hasil validasi tersebut digunakan untuk memperbaiki atau menyempurnakan bahan ajar awal yang telah dibuat sebelumnya agar bahan ajar interaktif tersebut lebih relevan untuk digunakan dan memenuhi kriteria kebutuhan standar pendidik dan siswa dalam kegiatan perkuliahan.

\section{Uji Coba Produk}

Setelah proses perbaikan produk bahan ajar interaktif, dilakukan uji coba produk. Menurut Borg dan Gall, (Sukmadinata, 2008) menyatakan bahwa uji coba lapangan awal yaitu uji coba lapangan pada 1 sampai 3 sekolah dengan 6 sampai dengan 12 subyek uji coba. Uji coba produk dilakukan dalam skala kecil, kemudian perbaikan produk dilakukan apabila diperlukan.

\section{Revisi Produk}

Tahap berikutnya adalah revisi produk. Revisi dilakukan apabila dalam uji skala produk terbatas terdapat kekurangan dan kelemahan kemudian berdasarkan masukan dan saran-saran hasil uji coba.

\section{Alur Pengembangan Media Berbasis Virtual Class Berbantuan Google Drive}

Untuk memperjelas proses dalam metode pengembangan dalam mewujudkan indikator keberhasilan, maka disusun alur penelitian yang dimodifikasi terhadap pengembangan Sugiyono, seperti pada Gambar 3 berikut.

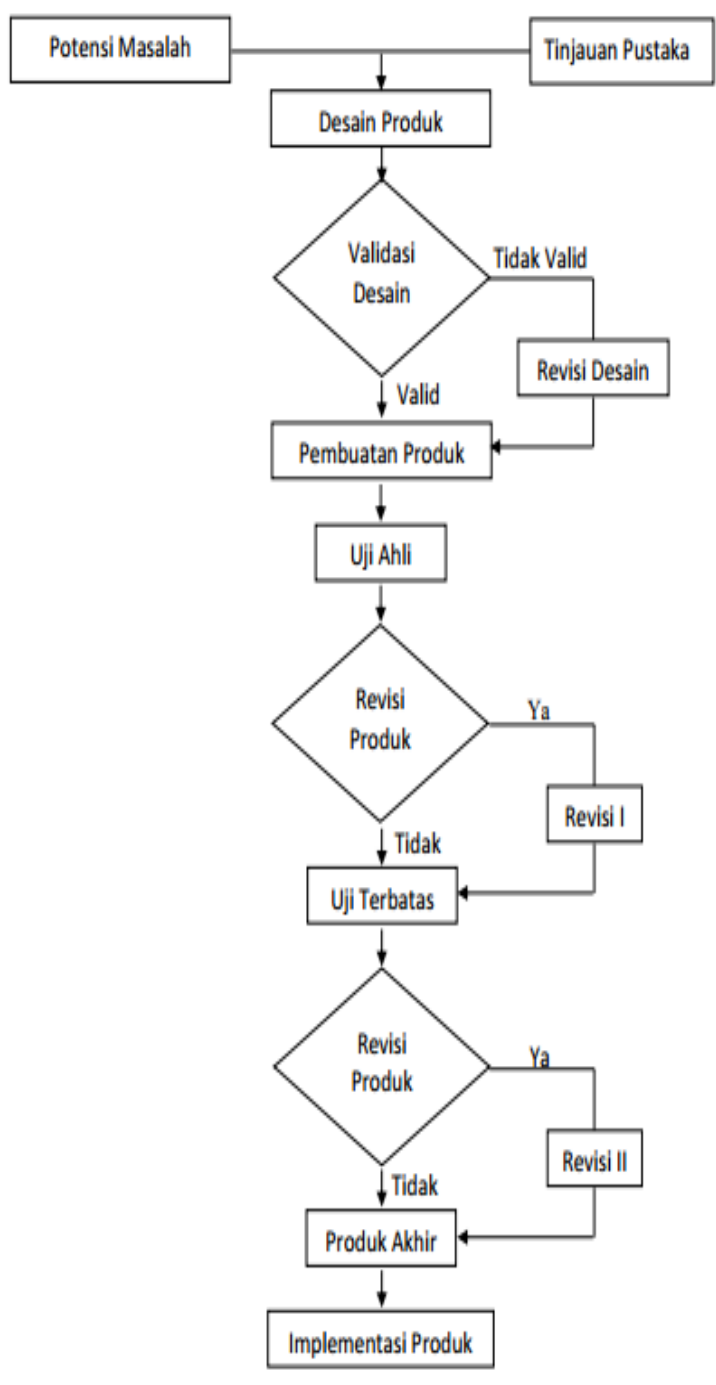

Gambar 3. Alur Pembuatan Media Pembelajaran.

\section{Instrumen Penelitian}

Instrumen yang digunakan dalam pengumpulan data pada penelitian ini berupa angket atau kuesioner. Angket merupakan teknik pengumpulan data yang dilakukan dengan cara member seperangkat pertanyaan tertulis kepada responden untuk dijawabnya (Sugiono, 2011).

Instrumen penelitian yang digunakan didasarkan pada variabel yang ingin diketahui, seperti instrumen tes mengacu pada indikator pemahaman konsep fisika, dan instrument angket kemandirian didasarkan pada indikator 
kemandirian belajar (Yuberti, 2015). Sedangkan indikator angket media pembelajaran didasarkan pada aspek $7 \mathrm{C}$ (Context, Content, Community, Customization, Communication, Connection, dan Collaboration). Adapun yang dimaksud aspek 7C menurut Hanafi (2009) penjelasannya sebagai berikut:

1. Context adalah layout atau desain tampilan suatu situs media sosial. Desain biasanya terdiri dari nilai estetika dan tampilan fungsional dengan paduan dari grafis, warna, dan fitur.

2. Content adalah isi yang disajikan dalam suatu situs media sosial, biasanya seperti: profil, pengaturan yang berupa teks, gambar, maupun video.

3. Community merupakan sebuah jalinan hubungan yang dibangun berdasarkan kepentingan yang sama. Biasanya ditandai dengan fasilitas daftar untuk login.

4. Customization adalah fasilitas yang diberikan bagi pengguna yang sudah menjadi anggota untuk dapat mengubah data dirinya pada fasilitas ubah profilnya.

5. Communication adalah merupakan suatu hubungan dengan melakukan pertukaran, baik itu broadcast (antara admin ke pengguna, antarpengguna) dan interaktif (perusahaan dan pengguna).

6. Connection merupakan link yang disediakan didalam situs media sosial untuk berhubungan dengan laman yang lain.

7. Collaboration memungkinkan untuk situasi dimana dua atau lebih orang belajar atau mencoba untuk belajar sesuatu bersama-sama.

\section{E. Analisis Data}

Terdapat tiga angket uji ahli diantaranya yaitu angket uji ahli fisika komputasi, angket uji ahli pendidikan, dan angket uji multimedia. Ketiga angket uji ahli tersebut merupakan angket tertutup. Pengolahan data angket uji ahli pada penelitian ini menggunakan numerical rating scale. Tahap numerical rating scale adalah pernyataan tentang kualitas tertentu dari sesuatu yang akan diukur, yang diikuti oleh angka yang menunjukkan skor sesuatu yang diukur (Widoyoko, 2012). Selain angket untuk uji ahli, terdapat dua angket untuk uji terbatas (Rohmani et al., 2015)

Setiap butir pernyataan angket memiliki skala pengukuran dari skor 1 sampai skor 4 dengan alternatif jawaban yang berbeda.

Tabel 1. Skor dan alternatif jawaban angket

\begin{tabular}{cc}
\hline Skor & Alternative jawaban \\
\hline 4 & Sangat Setuju \\
3 & Setuju \\
2 & Tidak Setuju \\
1 & Sangat Tidak Setuju \\
\hline
\end{tabular}

Setelah data terkumpul, lalu menghitung skor rata-rata dengan rumus:

$\mathrm{M}=\left(\sum \mathrm{fx}\right) / \mathrm{N}$

Keterangan:

$\mathrm{M}=$ Rata-rata Skor

$\Sigma F x=$ Jumlah skor yang diperoleh

$\mathrm{N}=$ Jumlah komponen yang divalidasi

Dengan kriteria pengambilan keputusan validasi dari nilai rata-rata validator pada Tabel 2 sebagai berikut.

Tabel 2. Kategori Validasi

\begin{tabular}{cc}
\hline Interval Rata-rata skor & Kategori \\
\hline $3.25 \leq \mathrm{x} \leq 4$ & Sangat Valid \\
$2.5 \leq \mathrm{x}<3.25$ & Valid \\
$1.75 \leq \mathrm{x}<2.5$ & Kurang Valid \\
$1 \leq \mathrm{x}<1.75$ & Tidak Valid \\
\hline
\end{tabular}

\section{F. Indikator Keberhasilan}

Indikator keberhasilan dalam penelitian ini yaitu terselesaikannya 
produk berupa pengembangan media pembelajaran berbasis Virtual Class berbantuan Google Drive. Maksud dari terselesaikannya produk ialah produk yang dibuat sudah melalui tahap penelitian pengembangan dan dengan kriteria ketercapaian bahan ajar sudah mencapai $70 \%$ dari uji ahli (Sugiyono, 2013).

\section{HASIL DAN PEMBAHASAN}

\section{Tampilan Media Pembelajaran Virtual Class}

Berikut disajikan tampilan produk media pembelajaran Virtual Class yang dikembangkan.

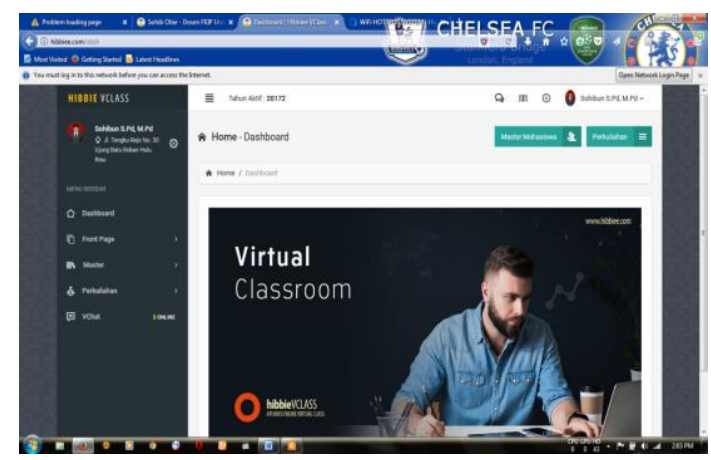

Gambar 4. Tampilan Awal Website Virtual Class

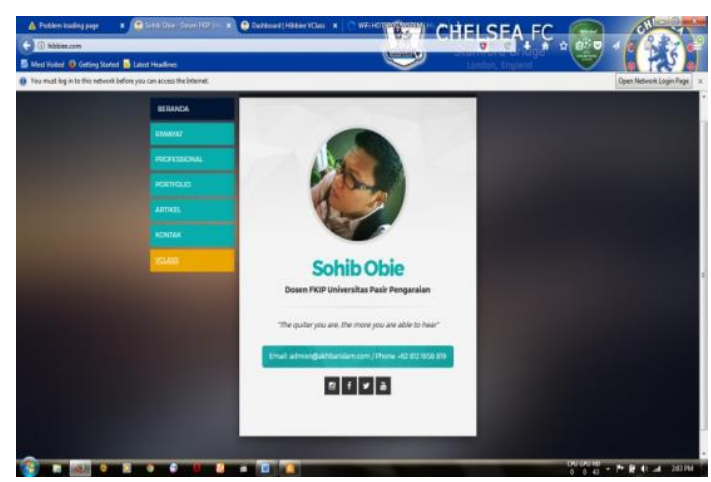

Gambar 5. Tampilan Website setelah Login

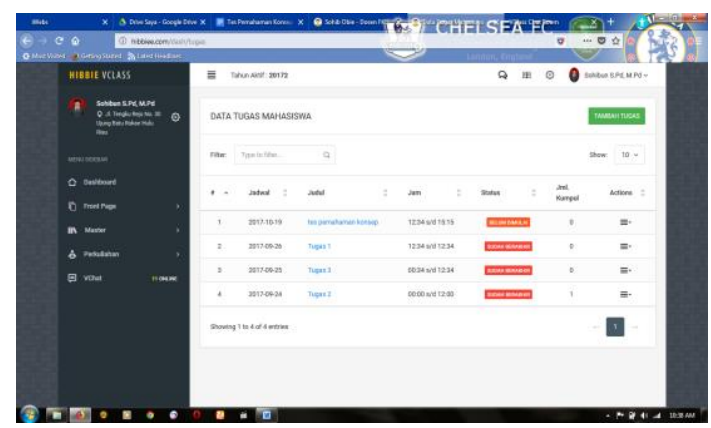

Gambar 6. Tampilan Website Virtual Class saat Perkuliahan Berlangsung

\section{Validasi Media}

Berdasarkan hasil validitas para ahli terhadap media pembelajaran Virtual Class berbasis Google Drive diperoleh data yang dirangkum dan disajikan dalam Tabel 3 berikut.

Tabel 3. Hasil Validasi

\begin{tabular}{lllll}
\hline & & \multicolumn{4}{c}{ Validator } \\
\cline { 2 - 5 } No. Pernyataan & 1 & 2 & 3 & 4
\end{tabular}

\begin{tabular}{|c|c|c|c|c|c|}
\hline \multicolumn{6}{|c|}{ A. Aspek Didaktik } \\
\hline 1 & $\begin{array}{l}\text { Media pembelajaran } \\
\text { virtual class } \\
\text { berbantuan google } \\
\text { drive ini dirancang } \\
\text { dengan desain } \\
\text { menarik. }\end{array}$ & 3 & 4 & 3 & 3 \\
\hline & $\begin{array}{ll}\text { Penyajian } & \text { materi } \\
\text { dalam } & \text { media } \\
\text { pembelajaran } & \text { virtual }\end{array}$ & & & & \\
\hline 2 & $\begin{array}{lr}\text { class } & \text { berbantuan } \\
\text { google } & \text { drive } \\
\text { disajikan } & \text { dengan } \\
\text { menarik } & \end{array}$ & 3 & 3 & 4 & 4 \\
\hline & $\begin{array}{l}\text { Menu pada media } \\
\text { pembelajaran virtual }\end{array}$ & & & & \\
\hline 3 & $\begin{array}{lr}\text { class } & \text { berbantuan } \\
\text { google } & \text { drive } \\
\text { memudahkah untuk } & \text { proses perkuliahan }\end{array}$ & 4 & 3 & 4 & 4 \\
\hline & $\begin{array}{l}\text { Media pembelajaran } \\
\text { virtual class }\end{array}$ & & & & \\
\hline 4 & $\begin{array}{l}\text { berbantuan google } \\
\text { drive mudah diakses } \\
\text { dan praktis }\end{array}$ & 3 & 3 & 3 & 4 \\
\hline & $\begin{array}{l}\text { B. Aspek Isi dan } \\
\text { Tampilan }\end{array}$ & & & & \\
\hline & $\begin{array}{l}\text { Materi pada media } \\
\text { pembelajaran virtual } \\
\text { class berbantuan }\end{array}$ & & & & \\
\hline 5 & $\begin{array}{l}\text { google drive ini } \\
\text { disesuaikan dengan } \\
\text { kompetensi dasar }\end{array}$ & 4 & 4 & 4 & 3 \\
\hline & $\begin{array}{l}\text { Tulisan yang } \\
\text { terdapat pada media } \\
\text { pembelajaran virtual }\end{array}$ & & & & \\
\hline 6 & $\begin{array}{l}\text { class berbantuan } \\
\text { google drive ini } \\
\text { dapat dibaca dan } \\
\text { dilihat dengan jelas }\end{array}$ & 3 & 4 & 4 & 4 \\
\hline
\end{tabular}




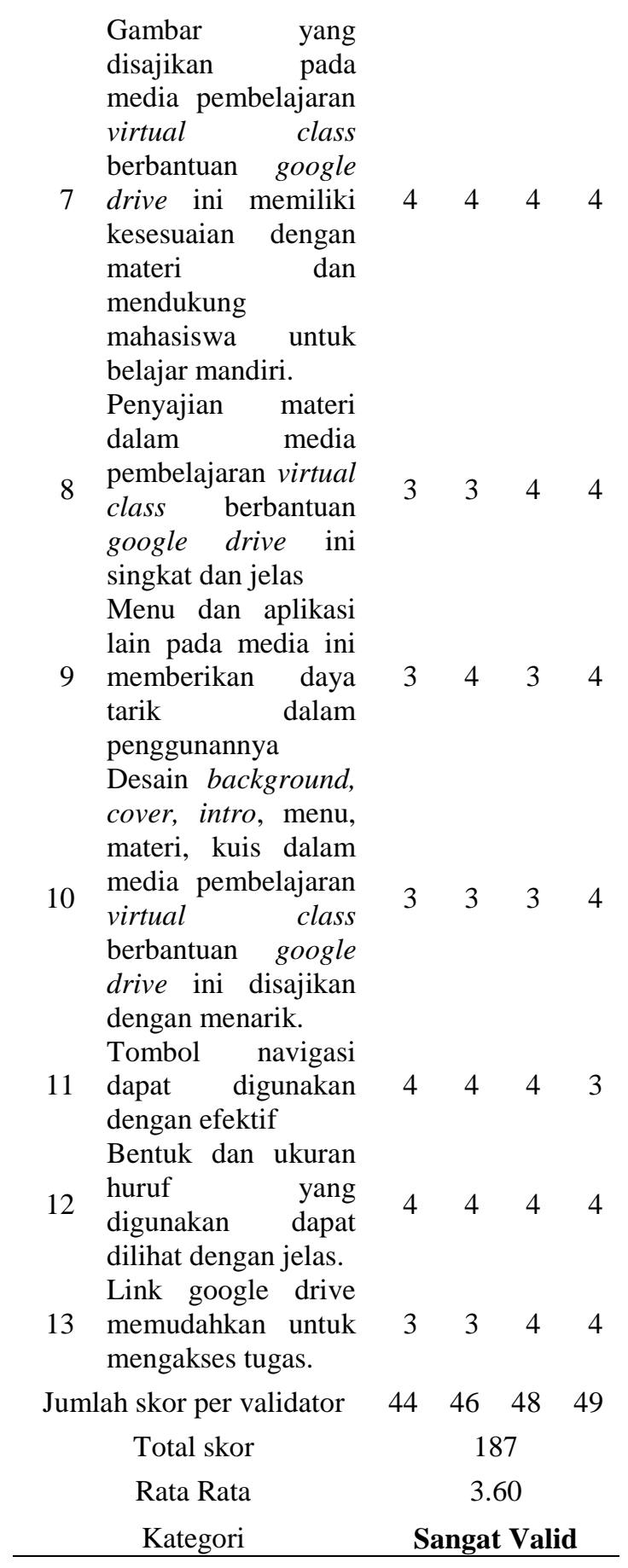

\section{Pembahasan}

Berdasarkan hasil perhitungan angket validasi ahli yang diberikan kepada ahli pembelajaran fisika, ahli materi fisika, dan ahli fisika komputasi didapatkan skor validitas sebesar 3,60 dengan kategori "sangat valid". Sehingga secara keseluruhan dapat dikatakan bahwa media pembelajaran Virtual Class berbasis Google Drive sangat direkomendasikan untuk digunakan. Validitas dilihat dari dua aspek yaitu aspek aspek isi dan tampilan dengan memperhatikan kebahasaan dan ketepatan fungsi dari media tersebut.

Implementasi produk sudah diterapkan dan digunakan dalam perkuliahan matakuliah termodinamika pada program studi pendidikan fisika FKIP Universitas Pasir Pengaraian. Setelah menggunakan pembelajaran Virtual Class berbasis Google Drive, kemandirian belajar mahasiswa meningkat. Hasil pengamatan menunjukkan bahwa mahasiswa lebih banyak belajar melalui Virtual Class untuk menunjang pembelajaran mereka di kelas.

\section{SIMPULAN DAN SARAN}

Dari analisis validitas produk yang dihasilkan, maka media pembelajaran virtual class berbantuan google drive bisa dijadikan inovasi dalam pembelajaran saat proses perkuliahan, karena hasil dari penelitian sudah dalam kategori sangat valid. Adapun saran dalam penelitian ini adalah media yang dihasilkan ditambah dengan video demonstrasi perkuliahan secara online langsung saat perkuliahan dilaksanakan.

\section{DAFTAR PUSTAKA}

Asyhari, A., \& Diani, R. (2017). Pembelajaran Fisika Berbasis Web Enhanced Course: Mengembangkan Web-logs Pembelajaran Fisika Dasar 1. Jurnal Inovasi Teknologi Pendidikan, 4(1), 13-25.

Eko Purwanto, A., Hendri, M., \& Susanti, N. (2016). Studi Perbandingan Hasil Belajar Siswa Mengunakan Media Phet Simulations Dengan Alat Peraga Pada Pokok Bahasan Listrik Magnet Di Kelas IX SMPN 12 Kabupaten Tebo. Jurnal Pendidikan Fisika, 1(1), 22-27.

Eliana, E. D. ., Senam, Wilujeng, I., \& Jumaidi. (2016). The Effectiveness 
Of Project-Based E-learning to Improve ICT Literacy. Jurnal Pendidikan IPA Indonesia, 5(1), 5155.

https://doi.org/10.15294/jpii.v5i1.57 89

Gumrowi, A. (2016). Meningkatkan hasil belajar listrik dinamik menggunakan strategi pembelajaran team assisted individualization melalui simulasi crocodile physics. Jurnal Ilmiah Pendidikan Fisika Al-Biruni, 5(April), 105-111. https://doi.org/10.24042/jpifalbiruni. v5i1.110

Gunawan, Harjono, A., \& Imran. (2016). Pengaruh Multimedia Interaktif dan Gaya Belajar Terhadap Penguasaaan Konsep Kalor Siswa. Jurnal Pendidikan Fisika Indonesia, 12(2), 118-125.

https://doi.org/10.15294/jpfi.v12i2.5 018

Hanafi. (2009). Pembelajaran Sejarah Kebudayaan Islam. Jakarta Pusat: Departemen Agama RI.

Irwandani. (2016). Potensi media sosial dalam mempopulerkan konten sains islam. Jurnal Keguruan Dan Ilmu Tarbiyah, 1(2), 173-177.

Mahbub, M. Z., Kirana, T., \& Poedjiastoeti, S. (2016). Development Of STAD Cooperative Baased Learning Set Assisted With Animation Media To Enhanche Student's Learning Outcome In MTS. Jurnal Pendidikan IPA Indonesia, 5(2), 247-255. https://doi.org/10.15294/jpii.v5i2.60 04

Mihardi, S., \& Derlina. (2015). Implementation Of Inquiry Training Model In Learning Physics To Improve Student Formal Thinking Ability. Jurnal Pendidikan Fisika Indonesia, 11(2), 162-169. https://doi.org/10.15294/jpfi

Mulyadi, E. (2015). Penerapan Model Project Based Learning untuk
Meningkatkan Kinerja dan Prestasi Belajar Fisika Siswa SMK. Jurnal Pendidikan Teknologi Dan Kejuruan, 22(4), 385-395.

Rohmani, S., Sunarno, W., \& Siti Amanah, N. (2015). Pembelajaran Fisika Menggunakan Model POE ( Prediction , Observation , And Explanation) Melalui Metode Eksperimen dan Proyek Ditinjau dari Kreativitas Dan Sikap Ilmiah Siswa. Jurnal Inkuiri, 4(4), 10-15.

Sugiono. (2011). Metode Penelitian Kuantitatif, Kualitatif dan $R \& D$. Bandung: Alfabeta.

Sugiyono. (2013). Memahami penelitian kualitatif. Bandung: Alfabeta.

Sukmadinata. (2008). Metode Penelitian Tindakan. Bandung: PT Remaja Rosdakarya.

widoyoko. (2012). Teknik Penyusunan Instrumen Penelitian. Yogyakarta: Pustaka Belajar.

Wijayanti, W., Maharta, N., \& Suana, W. (2017). Pengembangan Perangkat Blended Learning Berbasis Learning Management System pada Materi Listrik Dinamis. Jurnal Ilmiah Pendidikan Fisika Al-Biruni, 6(1), 112.

https://doi.org/10.24042/jpifalbiruni. v6i1.581

Woodrich, M., \& Fan, Y. (2017). Google Docs As A Tool For Collaborative Writing In The Middle School Classroom. Journal Of Information Technology Education Research, 16, 391-410.

Yuberti. (2015). Online Group Discussion pada Mata Kuliah Teknologi Pembelajaran Fisika. Jurnal Ilmiah Pendidikan Fisika Al-Biruni, 4(2), 145-153. https://doi.org/10.24042/jpifalbiruni. v4i2.88 